\title{
Magnetic Compression Anastomosis for the Treatment of Post- Transplant Biliary Stricture
}

\author{
Sung III Jang, Jae Hee Cho and Dong Ki Lee \\ Department of Internal Medicine, Gangnam Severance Hospital, Yonsei University College of Medicine, Seoul, Korea
}

A number of different conditions can lead to a bile duct stricture. These strictures are particularly common after biliary operations, including living-donor liver transplantation. Endoscopic and percutaneous methods have high success rates in treating benign biliary strictures. However, these conventional methods are difficult to manage when a guidewire cannot be passed through areas of severe stenosis or complete obstruction. Magnetic compression anastomosis has emerged as an alternative nonsurgical treatment method to avoid the mortality and morbidity risks of reoperation. The feasibility and safety of magnetic compression anastomosis have been reported in several experimental and clinical studies in patients with biliobiliary and bilioenteric strictures. Magnetic compression anastomosis is a minimally traumatic and highly effective procedure, and represents a new paradigm for benign biliary strictures that are difficult to treat with conventional methods. Clin Endosc 2020;53:266-275

Key Words: Anastomotic stricture; Benign biliary stricture; Magnetic compression anastomosis

\section{INTRODUCTION}

Despite continuing advances in surgical techniques, several complications in the biliary duct may occur after biliary surgery. Benign biliary strictures (BBSs) develop in 15\%-20\% of patients undergoing orthotopic liver transplantation (OLT) and in 19\%-40\% of those undergoing living-donor liver transplantation (LDLT). ${ }^{1}$ They also occur in $0.4 \%-0.6 \%$ of patients undergoing laparoscopic cholecystectomy. The cause of BBSs after liver transplantation may include hypertrophic changes and ischemia due to intraoperative damage to the blood vessels supplying the bile duct. These strictures are difficult to manage because of the acutely angulated and tortuous bile duct at the anastomotic site. ${ }^{3-6}$ Although BBSs are the most

Received: April 9, 2020 Revised: May 10,2020

Accepted: May 11, 2020

Correspondence: Sung Ill Jang

Department of Internal Medicine, Gangnam Severance Hospital, Yonsei University College of Medicine, 211 Eonju-ro, Gangnam-gu, Seoul 06273, Korea Tel: +82-2-2019-3310, Fax: +82-2-3463-3882, E-mail: aerojsi@yuhs.ac ORCID: https://orcid.org/0000-0003-4937-6167

(c) This is an Open Access article distributed under the terms of the Creative Commons Attribution Non-Commercial License (http://creativecommons.org/ licenses/by-nc/3.0) which permits unrestricted non-commercial use, distribution, and reproduction in any medium, provided the original work is properly cited. common complication after biliary surgery, no standardized treatment has been established for their management. ${ }^{7-10}$

In the initial years of biliary operation, most bile duct complications were treated surgically. However, surgical treatment has high rates of morbidity and mortality, and cannot be recommended for patients with inflammation in the bile duct. ${ }^{11}$ With the development of percutaneous transhepatic biliary drainage (PTBD) as an interventional radiologic procedure, recanalization of BBSs using an interventional technique has become possible. Insertion of multiple plastic stents (MPSs) or metal stents with or without balloon dilation through endoscopic retrograde cholangiopancreatography (ERCP) has also shown good results in the treatment of BBSs. ${ }^{5}$ Recanalization of BBSs is possible with a high resolution rate owing to advances in nonsurgical methods such as endoscopic and percutaneous techniques. Therefore, nonsurgical treatment of BBSs after biliary surgery is safer and more effective than surgical treatment. ${ }^{9,12}$

However, endoscopic or percutaneous treatment cannot be successful when it is impossible to place a guidewire percutaneously or endoscopically through the BBS owing to complete obstruction and severe stricture in the bile duct. In these cases, patients should have an external PTBD catheter to drain bile, which places a major burden on the patient by lowering the 
quality of life and conferring a high risk of infection.

Magnetic compression anastomosis (MCA) has been applied as a nonsurgical technique for reconstructing a refractory or completely obstructing BBS that cannot be resolved with conventional methods. ${ }^{13-24} \mathrm{MCA}$ is a method of recanalizing the obstructed bile duct by inserting magnets at both ends of the stenosis, inducing necrosis of the stenotic lesion through the pulling force of magnets. In this review, the principle and clinical results of MCA will be discussed with respect to two types of strictures: biliobiliary strictures and bilioenteric strictures.

\section{INDICATIONS FOR MCA}

The development of endoscopic and percutaneous treatments has enabled the resolution of BBSs. ${ }^{25-29}$ However, nonsurgical treatments cannot resolve severely narrowed or completely occluded bile ducts in which passage of a guidewire or dye is impossible. Accordingly, the indications for MCA are severe stenosis or complete obstruction of the bile duct that cannot be treated with usual endoscopic or percutaneous methods (Fig. 1). ${ }^{11,18,21-23,30-32}$

\section{PRE-ASSESSMENT FOR SUCCESSFUL MCA}

Pre-MCA assessment is needed to plan the approximation of magnets and to predict outcomes. Factors affecting the success of MCA include the length of the stricture, shape of the bile duct, power of the magnets, and axis of the bile duct. MCA may fail when the stricture is long and the bile duct is tapered or twisted in shape. ${ }^{22,23}$ The longer the stricture, the weaker the magnetic power between the two magnets. If the magnetic force is too weak, tissue necrosis due to magnetic compression cannot occur and a new fistula does not form. Therefore, exact evaluation of the length of the stricture is essential for a successful approximation of magnets before MCA. However, radiologic studies (computed tomography, ultrasonography, and magnetic resonance cholangiopancreatography) cannot exactly assess the length of a stricture. Cholangiographic assessment of biliary ducts using ERCP or PTBD may be feasible; however, they are invasive procedures.

Evaluating the axis and shape of the bile duct is also substantial for the success of MCA. Even if the stricture is relatively short, the magnet cannot fully reach the stricture if the bile duct is tapered and rotated. In tapered and rotated bile ducts, MCA can fail because the true distance between the two magnets will be longer than the measured stricture. ${ }^{22}$ Moreover,
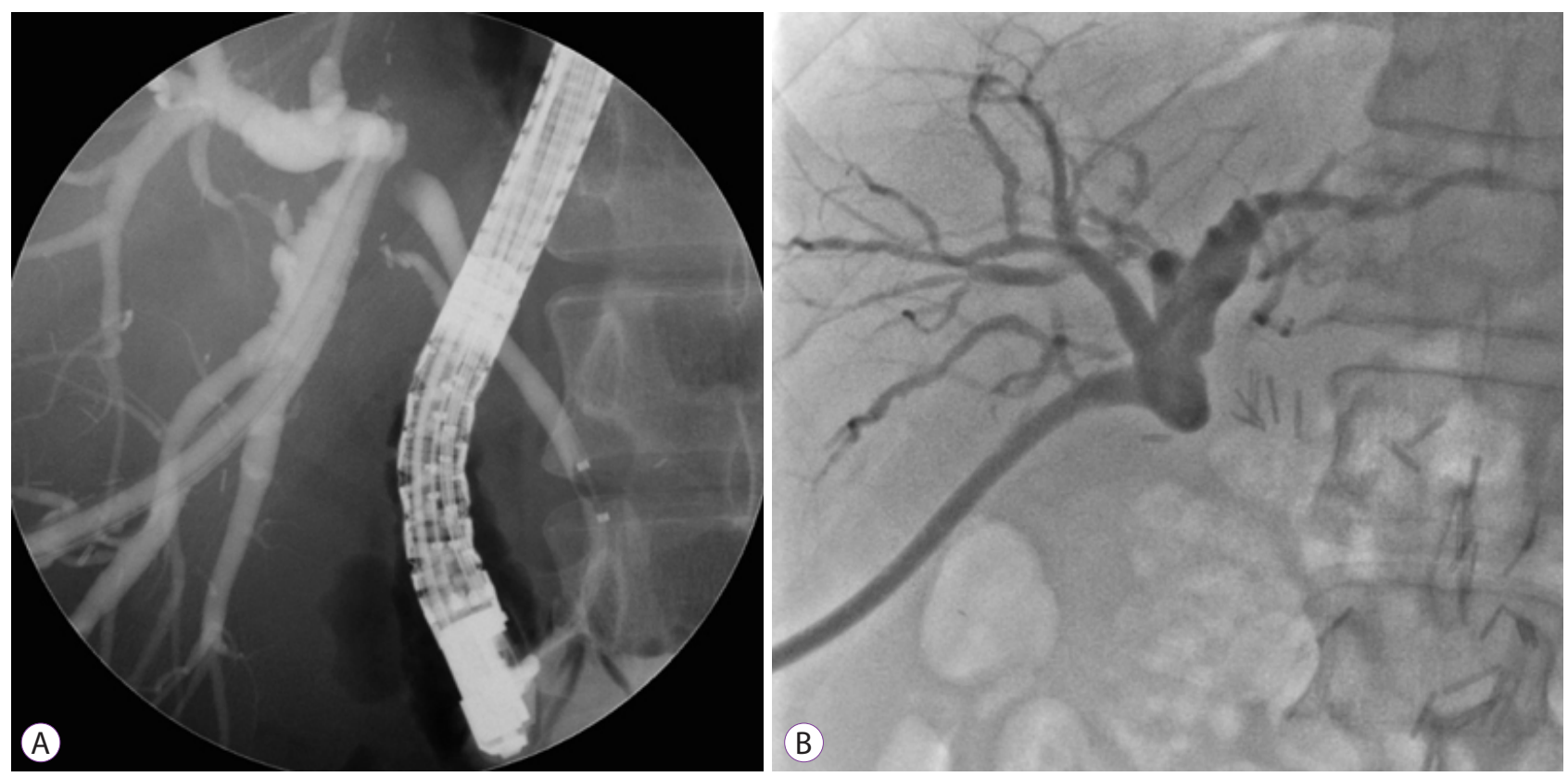

Fig. 1. Cholangiogram showing indications for magnetic compression anastomosis (MCA). MCA can be applied for a refractory benign biliary stricture that could not be resolved using conventional endoscopic or percutaneous methods because of complete obstruction through which neither (A) a guidewire nor (B) dye is able to pass. 
the axis of the bile ducts is important because it determines the direction of alignment of the two magnets. If the magnets are aligned parallel, MCA fails owing to weak magnetic power. ${ }^{22,23}$ Noninvasive radiologic tools have a limitation in identifying suitable MCA candidates because they cannot accurately evaluate the stricture length and shape, as well as the axis of the bile duct, for a successful MCA. Therefore, preassessments for MCA has limitations and the success of MCA could only be actually predicted while performing the procedure until now.

\section{MCA PROCEDURE}

The process of MCA is divided into four steps (Fig. 2): formation of the tract for magnet delivery, approximation of magnets, removal of the approximated magnets, and maintenance and removal of the internal catheter. ${ }^{22,24}$ The common routes of magnet delivery are percutaneous and peroral. The percutaneous tract for the delivery of magnets is formed using the PTBD tract. The PTBD tract is sequentially dilated to 16 Fr, and the PTBD catheter is changed to an 18 Fr sheath in the process of MCA approximation. This process allows the insertion of magnets without difficulties and duct injury through the sheath during the movement of the magnets. The peroral route for magnet approximation is performed using ERCP. A retrieval fully covered self-expandable metal stent (FCSEMS) is inserted into the common bile duct (CBD) to deliver the magnet via the oral route after an endoscopic sphincterotomy.

A silk thread attached to one magnet is fixed to a polypectomy snare, and the magnet is moved to the stricture site through the PTBD tract. Another polypectomy snare is passed through the channel of an ERCP scope, and the other magnet is fixed in front of the scope. The magnet is moved to the anastomosis site through the FCSEMS. This process is performed
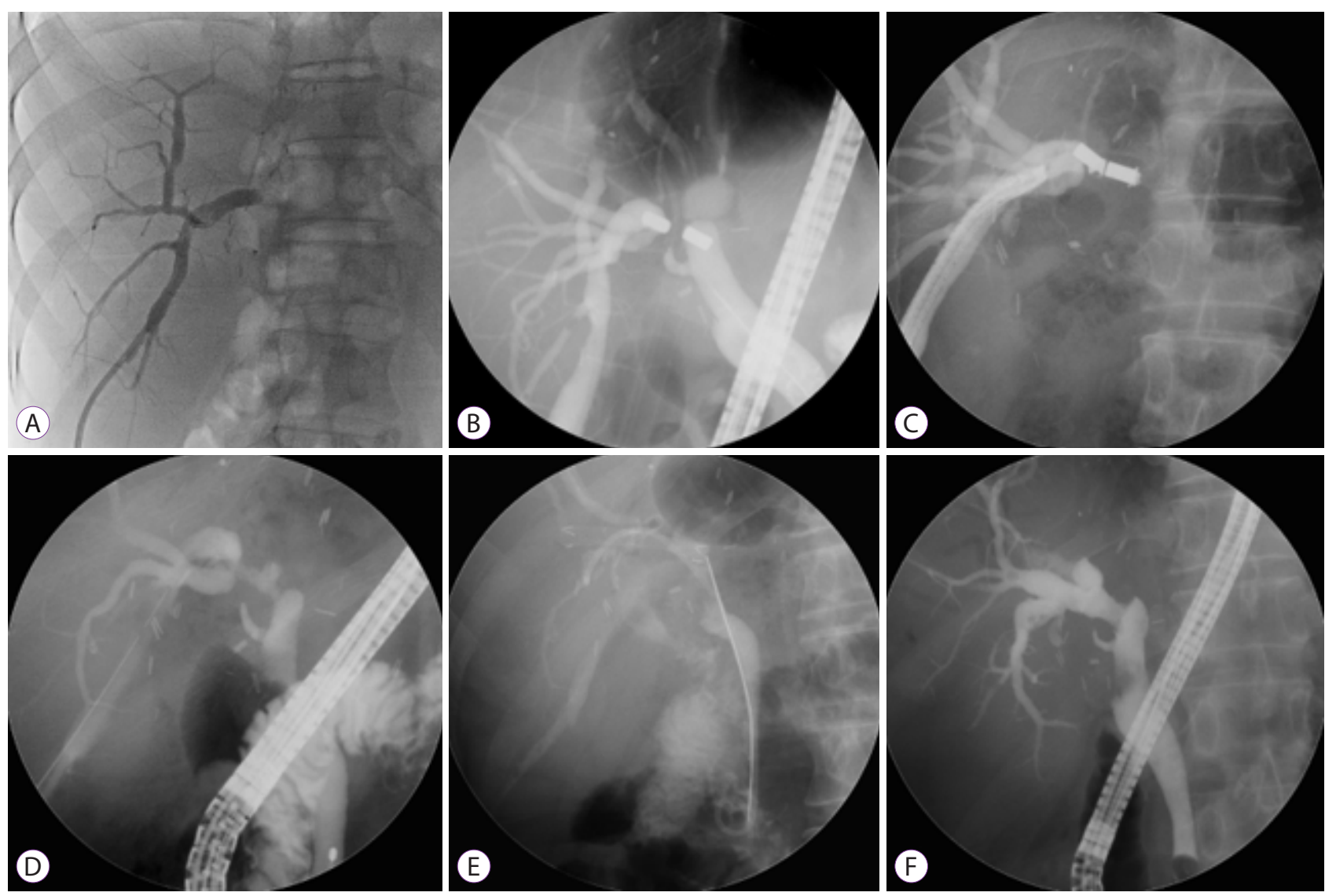

Fig. 2. Magnetic compression anastomosis for a stricture after living-donor liver transplantation. (A) A percutaneous transhepatic biliary drainage (PTBD) catheter was inserted and dilated to $16 \mathrm{Fr}$. (B) One magnet was delivered through the PTBD tract, and the other magnet was moved using an endoscopic retrograde cholangiopancreatography scope through the common bile duct. The approximation of magnets was successful and the PTBD catheter was inserted. (C) The approximated magnets were removed using percutaneous transhepatic cholangioscopy via the PTBD tract. (D) The cholangiogram showed a recanalized tract after magnet removal. (E) A retrievable, fully covered self-expandable metal stent (FCSEMS) was inserted for 6 months (exchanging every 3 months). (F) Finally, formation of a new fistula was confirmed after the removal of the indwelling FCSEMS. 
under controlled aseptic conditions with the same level of infection control as for the operating room, and no MCA procedure-related infection has been reported.

After one magnet is moved to the stricture via the 18- $\mathrm{Fr}$ sheath, the other magnet is applied to the stricture site through an FCSEMS in the CBD. After the placement of the two magnets, the magnets are approximated through their attraction to each other. The distance between the two magnets is made shorter by pushing them using a balloon catheter through the PTBD and ERCP tracts. Radiologic cholangiography is performed to confirm the approximation of the two magnets. After confirming the approximation, the 18-Fr sheath is replaced with an indwelling 16-Fr PTBD catheter and the FCSEMS placed in the CBD is removed.

After the approximation, the two magnets compress the stricture tissue, leading to ischemic necrosis of the stricture tissue. As the magnets gradually become closer to each other, the ischemic necrosis process accelerates and a new fistula is finally formed. The magnets after full approximation can spontaneously migrate into the $\mathrm{CBD}$ or enteric tract through the new fistula. A plain abdominal radiograph is obtained at 2-week intervals for 6-8 weeks after the successful approximation of magnets to confirm the migration of the magnets through the fistula tract. If the magnets remain in the stricture site with close approximation after 10 weeks, they can be removed using percutaneous transhepatic cholangioscopy (PTCS). The mean duration for a successful magnet removal after magnet approximation was reported to be 53.3 days (range, 9-181 days) for biliobiliary strictures and 7-40 days for bilioenteric strictures. ${ }^{33,34}$ The factors for successful magnet removal include the distance between the two magnets, the magnetic power of the two magnets, and the histologic characteristics of the stricture site.

Recanalized fistula is confirmed endoscopically under fluoroscopy after magnet removal. The mean indwelling duration of the PTCS catheter or an FCSEMS to maintain the new fistula tract is $4-6$ months. The PTCS catheter and FCSEMS have exhibited similar safety and efficacy for fistula maintenance. ${ }^{35}$ However, the FCSEMS is more convenient for patients because the PTCS catheter has a longer indwelling duration and requires more number of replacements.

\section{RESULTS OF MCA IN BILIOBILIARY STRICTURES}

\section{Post-living-donor liver transplantation strictures}

BBSs are a relatively common complication of liver transplantation. Extensive stripping of the blood vessels during the operation can cause ischemic injury ${ }^{4}$ and hypertrophic change ${ }^{3}$ promotes biliobiliary anastomotic strictures. ${ }^{5}$ Although the optimal strategy for BBSs has not been determined, nonsurgical approaches are more popular. The insertion of MPSs with or without balloon dilatation is currently the treatment of choice. ${ }^{36}$ The success rate of MPSs is approximately $70 \%-91 \%$ in patients with BBSs after deceased-donor liver transplantation and $60 \%-100 \%$ in those with BBSs after LDLT. ${ }^{36-39}$ FCSEMS has a similar stricture resolution rate to MPS, but the number of ERCP sessions is fewer. ${ }^{1,40}$ However, MPS and FCSEMS insertion cannot be applied when a guidewire cannot pass though the stricture.

The overall clinical success rate of MCA for biliobiliary strictures was reported to be $87.5 \%$, and the recurrence rate was $7.1 \%$ (Table 1). The clinical success rates of MCA differ according to the etiology of the stricture and the treatment method in biliobiliary strictures. ${ }^{41-45}$ Although surgery-related strictures and strictures due to stones have high resolution rates with endoscopic treatment, idiopathic and chronic pancreatitis-related strictures respond poorly to endoscopic management. ${ }^{46}$ The clinical success rate of endoscopic treatment for biliobiliary strictures is $90 \%$ in postoperative strictures but only $65 \%$ in strictures due to chronic pancreatitis. ${ }^{46}$ Moreover, the resolution rates of percutaneous treatment of biliobiliary strictures were reported to be from $61.4 \%$ to $90.9 \%{ }^{47-50} \mathrm{Al}$ though advances in conventional techniques have increased the clinical success rates, these methods are unsuccessful for severe stenotic strictures through which passage of a guidewire is impossible. Therefore, these methods cannot be used to resolve all biliobiliary strictures. Moreover, with conventional methods, the clinical resolution rates are lower than the technical success rates, because of stricture recurrence. Repeated pneumatic dilation can cause traumatic tissue injury and promote a fibrotic reaction resulting in the recurrence of strictures. $^{51}$

The early complication rates after MCA are not reported in most studies (Table 1). The main adverse event is mild cholangitis, which can be resolved with conservative treatment. ${ }^{22,23}$ The only reported adverse event occurring from magnet approximation to the removal of the indwelling catheter is a slight fever. ${ }^{34}$ Doppler ultrasound is performed to evaluate the vessel because the risk of vessel rupture is a concern during the early stages of MCA. ${ }^{17,19}$ However, no blood vessel rupture has been reported to date. As the magnets gradually get closer to each other during a long period after magnet approximation, the intervening vessels are not compressed or ruptured. The mean duration of full magnet approximation is 53.3 days in biliobiliary strictures and 7-40 days in bilioenteric strictures. ${ }^{23}$

No late adverse events and MCA procedure-related mortality have been reported during the follow-up. Adverse events related to magnets have not been reported because the mag- 
Table 1. Results of Magnetic Compression Anastomosis in Biliobiliary Strictures

\begin{tabular}{|c|c|c|c|c|c|c|}
\hline Study & Type of article & Age $(y r) / S e x$ & Reason for surgery & Previous surgery & $\begin{array}{c}\text { Distance } \\
\text { between } \\
\text { magnets }(\mathbf{m m})\end{array}$ & Anastomosis \\
\hline Mimuro et al. $(2003)^{17}$ & Case report & $76 / \mathrm{F}$ & Pancreatic cancer & DP & 12 & Partial \\
\hline Itoi et al. $(2005)^{18}$ & Case report & $76 / \mathrm{F}$ & Bile duct cancer & None & 8 & Partial \\
\hline Okajima et al. $(2005)^{30}$ & Case report & $44 / \mathrm{F}$ & Fulminant hepatitis & LDLT & 2 & Complete \\
\hline Akita et al. $(2008)^{41}$ & Case report & $34 / \mathrm{F}$ & N/A & LDLT & 2 & Complete \\
\hline Matsuno et al. $(2009)^{14}$ & Case report & $53 / \mathrm{M}$ & N/A & LDLT & 2 & Complete \\
\hline Itoi et al. $(2010)^{33}$ & Case report & $60 / \mathrm{M}$ & N/A & LDLT & N/A & Complete \\
\hline Itoi et al. $(2011)^{71}$ & Case report & $40 / \mathrm{F}$ & $\begin{array}{l}\text { Liver metastasis } \\
\text { from colon cancer }\end{array}$ & $\begin{array}{l}\text { Right three seg- } \\
\text { mental + S3 partial } \\
\text { hepatectomy }\end{array}$ & 15 & Complete \\
\hline Jang et al. $(2011)^{22}$ & Retrospective study & $\begin{array}{c}\text { Mean, 53.8/ } \\
M: F=9: 3\end{array}$ & $\begin{array}{l}\text { LC (3), HCC (7), } \\
\operatorname{HF}(2)\end{array}$ & LDLT & N/A & Complete \\
\hline Oya et al. $(2012)^{31}$ & Case report & $24 / \mathrm{M}$ & N/A & LDLT & N/A & Partial \\
\hline \multirow[t]{2}{*}{ Jang et al. $(2014)^{23}$} & Case report (2 patients) & $45 / \mathrm{M}$ & Abdominal trauma & Embolization & 4 & Complete \\
\hline & & $38 / \mathrm{F}$ & Cholecystitis & Cholecystitis & 6 & Complete \\
\hline Ersoz et al. $(2016)^{42}$ & Case report (6 patients) & $\begin{array}{c}\text { Mean, 54.8/ } \\
\mathrm{M}: \mathrm{F}=4: 2\end{array}$ & LC & LDLT & $5-15$ & Complete \\
\hline Jang et al. $(2017)^{24}$ & Retrospective study & $\begin{array}{l}\text { Mean, 53.4/ } \\
\mathrm{M}: \mathrm{F}=31: 8^{\mathrm{a})}\end{array}$ & $\begin{array}{l}\operatorname{LC}(18), \operatorname{HCC}(8), \\
\operatorname{HF}(3)^{b)}\end{array}$ & LDLT & N/A & Complete \\
\hline Parlak et al. $(2017)^{43}$ & Retrospective study & $\begin{array}{c}\text { Mean, 55.7/ } \\
M: F=6: 3\end{array}$ & $\mathrm{LC}$ & $\begin{array}{l}\operatorname{LDLT}(7) \\
\operatorname{OLT}(2)\end{array}$ & $2.5-6$ & Complete \\
\hline Jiang et al. $(2018)^{44}$ & Case report & $64 / F$ & $\begin{array}{l}\text { Liver metastasis } \\
\text { from rectal cancer }\end{array}$ & $\begin{array}{l}\text { Right partial hepa- } \\
\text { tectomy }\end{array}$ & N/A & Complete \\
\hline Li et al. $(2020)^{45}$ & Retrospective study & $\begin{array}{l}\text { Mean, 49/ } \\
M: F=7: 2\end{array}$ & $\mathrm{LC}$ & OLT & $2-7$ & Complete \\
\hline
\end{tabular}

DP, dorsal pancreatectomy; HCC, dorsal pancreatectomy; HF, hepatic failure; LC, liver cirrhosis; LDLT, living-donor liver transplantation; N/A, not available; OLT, orthotopic liver transplantation.

a) These age and sex data represent all 39 patients in the study, 35 of whom had biliobiliary strictures (which occurred after LDLT in 29 patients).

b) These numbers represent 29 patients with post-LDLT biliobiliary strictures.

nets are aseptic devices that do not induce an inflammatory or immune reaction in the bile duct. Moreover, no adverse events directly related to other equipment used in MCA have been reported because the MCA procedure is performed using conventional ERCP techniques and a PTBD tract. Therefore, the MCA procedure seems to be safe in patients undergoing liver transplantation or with an immunocompromised status.

The length of the stricture is an important consideration for a successful MCA. The strictures are usually longer and the shape is more tortuous in LDLT recipients than in OLT recipients. Moreover, the distance between the approximated magnets is shorter for bilioenteric anastomoses $(2-7 \mathrm{~mm})$ than for biliobiliary anastomoses $(2-15 \mathrm{~mm})$. The technical factors influencing the effectiveness of MCA are stricture length, duration from LDLT to stricture occurrence, shape of the bile duct, and magnetic power of the magnets. The maximal stricture length for a successful MCA has not been confirmed and needs to be evaluated.

MCA creates a new fistula tract through tissue necrosis instead of simple dilation of fibrotic tissue in BBSs; thus, the recurrence rate seems to be lower than that with other conventional treatments. The possibility of elastic recoiling in the fistula formed by MCA may be lower. Moreover, a PTBD catheter is not needed and the risk of infection is low after recanalization with MCA. However, the long-term efficacy of MCA should be clarified by further large-scale and long-term follow-up studies.

As MCA is applied in biliary strictures that could not be 
resolved using conventional methods, it is difficult to compare its advantages and disadvantages with those of conventional methods, and it cannot replace conventional methods. Currently, MCA is not widely used because the magnets and equipment used in MCA are not commercially available, and cases that are indicated for MCA are relatively rare.

\section{Post-orthotopic liver transplantation strictures}

BBSs are more frequent after LDLT than after OLT. ${ }^{52-56}$ Overall, the incidence of BBSs is $25 \%-32 \%$ after $\operatorname{LDLT}^{57-61}$ and $5 \%-15 \%$ after OLT. $39,60,62$ The higher incidence of post-LDLT strictures is due to technical aspects of the operation because ductal anastomosis between the donor and the recipient during LDLT is complicated. Moreover, the duct of the donor liver has many variants, including multiple bile ducts, a poor blood supplement, and a relatively short stump for the anastomosis. ${ }^{9,60,61,63}$

The MCA process in post-OLT strictures is the same as in
post-LDLT strictures (Fig. 3). The level of post-OLT strictures is more distal in the CBD than that of post-LDLT strictures. Post-OLT strictures are mid-level BBSs but post-LDLT strictures are high-level BBSs. In addition, intrahepatic ducts (IHDs) are more dilated but less angulated and tortuous in post-OLT strictures than in post-LDLT strictures. Therefore, MCA is more feasible and the success rate is high in post-OLT strictures (Fig. 3).

\section{Post-cholecystectomy strictures}

Bile duct injury during laparoscopic cholecystectomy has occurred with an incidence of $0.3 \%-0.6 \%$. ${ }^{64}$ The type of biliary injuries can be categorized according to the Bismuth, ${ }^{65}$ Strasberg, ${ }^{66}$ and Stewart-Way classifications. ${ }^{67}$ The Stewart-Way classification categorizes biliary injuries into four types according to the mechanism and anatomy. ${ }^{67}$ Stewart-Way class I injuries are immediately resolved during the operation. Stewart-Way class II injuries with stricture are managed with
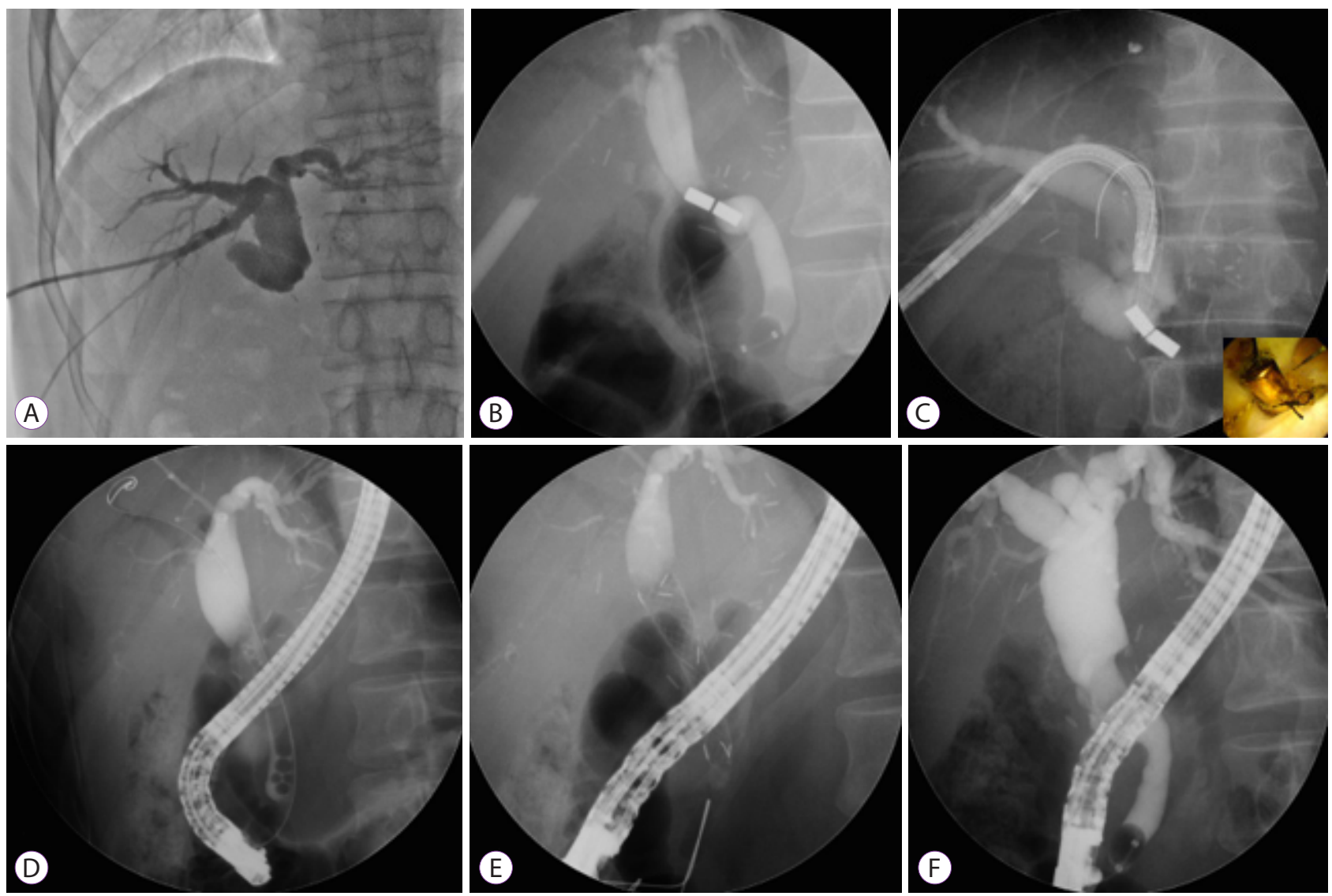

Fig. 3. Magnetic compression anastomosis for a stricture after orthotopic donor liver transplantation. (A) A percutaneous transhepatic biliary drainage (PTBD) catheter was inserted and dilated to $16 \mathrm{Fr}$. (B) One magnet was delivered through the PTBD tract, and the other magnet was moved using an endoscopic retrograde cholangiopancreatography (ERCP) scope through the common bile duct. The approximation of magnets was successful and the PTBD catheter was inserted. (C) The approximated magnets were removed using percutaneous transhepatic cholangioscopy via the PTBD tract and ERCP scope. The bottom right color photograph shows the approximated magnets. (D) Cholangiogram showing the recanalized tract after magnet removal. (E) A retrievable, fully covered self-expandable metal stent was inserted for 6 months (exchanging every 3 months). (F) The recanalized fistula was formed widely, compared with the cholangiogram in (D). 
insertion of MPSs and FCSEMS. Stewart-Way class III and IV injuries can be treated using multidisciplinary methods. ${ }^{68}$ A combined endoscopic-radiologic rendezvous technique is needed for complete transection of the main bile duct (Stewart-Way class III) and transection of a sectoral bile duct (Stewart-Way class IV). This technique can avoid surgical reintervention, and can reduce surgical morbidity and mortality. These endoscopic-radiologic rendezvous techniques for treating bile duct stenosis or complete obstruction are feasible only if the guidewire can pass through the stricture. MCA can be an alternative method for patients with Stewart-Way class III and IV ductal injuries that cannot be resolved using rendezvous techniques (Fig. 4). The procedure for MCA is similar to the procedures applied in patients with post-LDLT strictures.

\section{Other biliary strictures after surgery}

Bile duct injury and stricture may also occur after other hepatobiliary operations including hepatectomy. Complex dissection, poorly defined anatomy, or management of intraoperative bleeding by clipping can cause early-phase stricture. ${ }^{69}$ Late-phase stricture may result from ischemic injury in the bile ducts, and a stricture may not develop clinically until several years after the initial injury. Endoscopic treatment with MPS or FCSEMS insertion is a more preferred method for strictures after biliary surgery than percutaneous treatment, but multidisciplinary approaches involving endoscopists, radiologists, and surgeons are usually required to resolve these complicated BBSs. Usually, an endoscopic or percutaneous approach can be useful if the guidewire can pass through the BBS. However, MCA can be applied when these conventional methods cannot resolve the $\mathrm{BBS}$. The technique for MCA in this situation is also similar to that used for post-LDLT strictures.
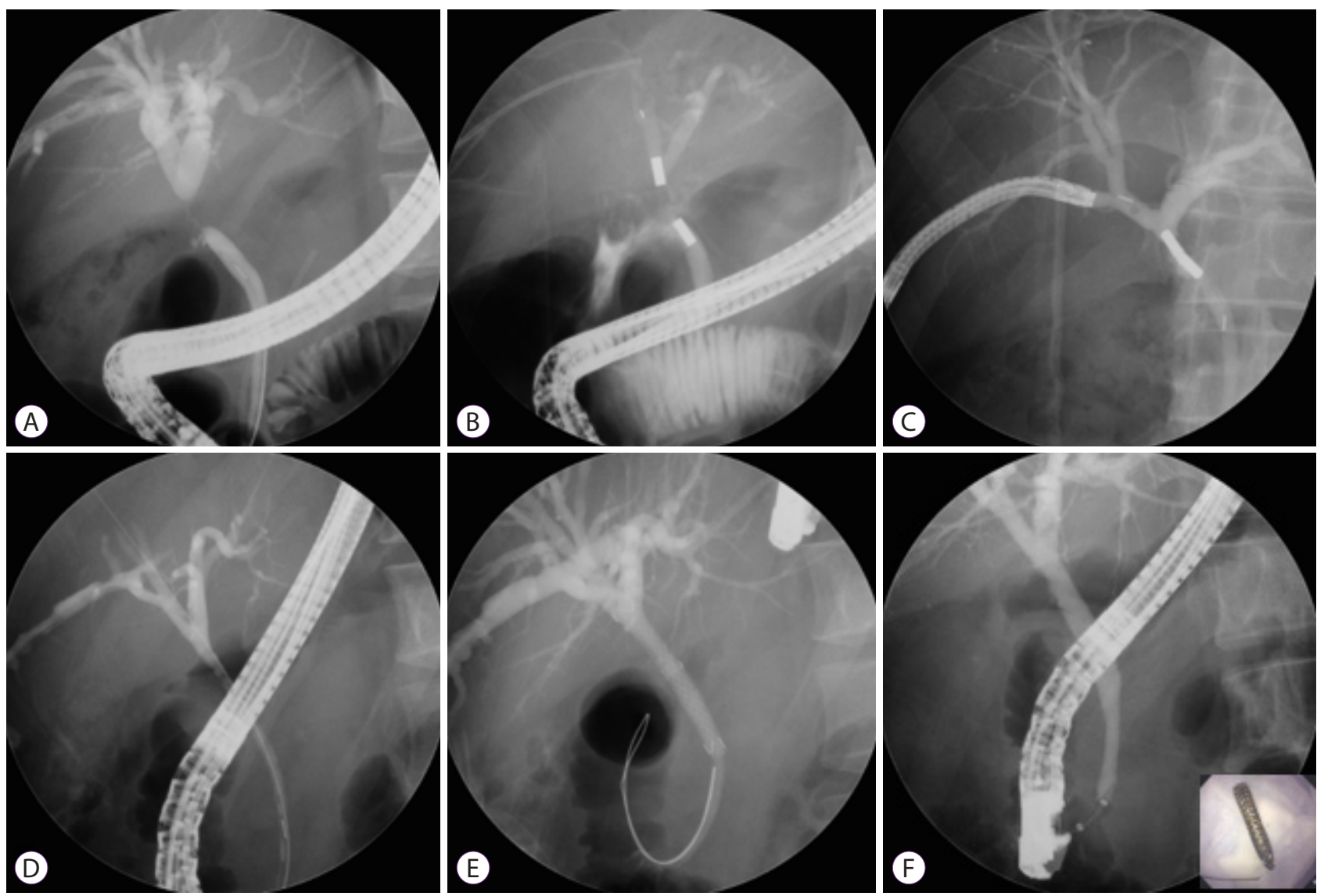

Fig. 4. Magnetic compression anastomosis for a post-cholecystectomy stricture. (A) Common hepatic duct stricture that occurred after laparoscopic cholecystectomy. (B) One magnet was moved through the percutaneous transhepatic biliary drainage (PTBD) tract, and a second magnet was delivered via the common bile duct using a duodenoscope. Magnet approximation was successful but the distance between two magnets was long. However, the two magnets moved closer to each other because of magnetic power, and magnet approximation was successful. (C) The approximated magnets were removed using percutaneous transhepatic cholangioscopy via the PTBD tract and endoscopic retrograde cholangiopancreatography scope. (D) Cholangiogram showing the recanalized tract after magnet removal. (E) A retrievable, fully covered self-expandable metal stent (FCSEMS) was inserted for 6 months (exchanging every 3 months). (F) Finally, formation of a new fistula was confirmed after the removal of the indwelling FCSEMS. The bottom right color photograph shows the removed FCSEMS. 


\section{MCA FOR BILIOENTERIC STRICTURES}

\section{Hepaticojejunostomy site strictures}

BBSs are caused by postoperative complications, especially after a Roux-en-Y reconstruction, which is the most common method of anastomosis in biliary surgery (Table 2). The mean distance between the approximated magnets was reported to be $4 \mathrm{~mm}$ (range, 2-7 $\mathrm{mm}$ ), and the duration from magnet approximation to magnet removal was 7-40 days. Complete resolution of the obstruction was accomplished in 41 of 42 patients (97.6\%), and no severe complications were observed. The recurrence rate was low (follow-up period: mean, 40 months; range, 2-53 months). One patient had restenosis at 6 days after the removal of the indwelling catheter, which was treated successfully and without difficulty with balloon dilation. $^{34}$

The difference in the MCA method between bilioenteric anastomosis strictures and biliobilary strictures is the route for magnet delivery. ${ }^{24,34,70}$ The delivery route for magnets in biliobiliary strictures is mainly the percutaneous-peroral tract.
However, the delivery routes for magnets in bilioenteric strictures are various and include the percutaneous-peroral tract, surgically formed percutaneous-enteric tract, or percutaneous-percutaneous tract. The method of magnet delivery to the percutaneous tract is similar to that described previously. With the peroral approach, a forward-viewing endoscope is used instead of an ERCP scope. ${ }^{23}$ A peroral approach with the forward-viewing endoscope is sometimes difficult in patients with long and redundant afferent loops. Single-balloon enteroscopy is feasible in these situations. ${ }^{71}$ If the endoscope cannot approach the stricture site, magnets can be delivered through a surgically formed percutaneous-enteric fistula. ${ }^{23}$ When the left and right IHDs are anastomosed separately to the jejunum and the stricture occurs in the right IHD, two PTCS scopes can be applied for MCA. ${ }^{72}$ One magnet is moved through the right IHD using one PTCS scope, and the other through the left IHD to approximate via the left IHD tract using another PTCS scope. The cases described above provide the possible methods of magnet delivery that can be applied in various situations.

Table 2. Results of Magnetic Compression Anastomosis in Bilioenteric Strictures

\begin{tabular}{|c|c|c|c|c|c|c|}
\hline Study & Type of article & $\begin{array}{l}\text { Age }(y r) / \\
\text { Sex }\end{array}$ & $\begin{array}{l}\text { Reason for opera- } \\
\text { tion }\end{array}$ & Previous operation & $\begin{array}{c}\text { Distance } \\
\text { between } \\
\text { magnets }(\mathrm{mm})\end{array}$ & Anastomosis \\
\hline Takao et al. $(2001)^{21}$ & Case report & $70 / \mathrm{M}$ & Gastric cancer & Subtotal gastrectomy (B-II) & 2 & Complete \\
\hline \multirow[t]{2}{*}{ Muraoka et al. $(2005)^{19}$} & Case report (2 & $1 / \mathrm{F}$ & Fulminant hepatitis & LDLT (left lobe) with R-Y & 2 & Complete \\
\hline & cases) & $57 / \mathrm{M}$ & $\mathrm{LC}+\mathrm{HCC}$ & LDLT (right lobe) with R-Y & 5 & Complete \\
\hline Yukawa et al. $(2008)^{20}$ & Case report & $83 / \mathrm{M}$ & $\begin{array}{l}\text { Gastric and gall- } \\
\text { bladder cancer }\end{array}$ & $\begin{array}{l}\text { Distal gastrectomy with } \\
\text { R-Y and cholecystectomy }\end{array}$ & $\mathrm{N} / \mathrm{A}$ & Complete \\
\hline Avaliani et al. $(2009)^{11}$ & $\begin{array}{l}\text { Retrospective } \\
\text { study }\end{array}$ & $\begin{array}{c}\text { Mean, 64/ } \\
M: F=9: 25\end{array}$ & $\begin{array}{l}\text { Cancer of VA (7), } \\
\text { pancreatic cancer } \\
(21), \text { CCC }(6)\end{array}$ & None & N/A & $\begin{array}{c}\text { Complete } \\
\text { (except } 1 \text { case) }\end{array}$ \\
\hline Suyama et al. $(2010)^{32}$ & Case report & $78 / \mathrm{M}$ & Gallbladder cancer & $\begin{array}{l}\text { Radical cholecystectomy } \\
\text { with R-Y }\end{array}$ & N/A & Complete \\
\hline Itoi et al. $(2011)^{71}$ & Case report & $60 / \mathrm{F}$ & CCC & $\begin{array}{l}\text { Expanded left lobectomy } \\
\text { with R-Y }\end{array}$ & 2 & Complete \\
\hline \multirow[t]{3}{*}{ Jang et al. $(2014)^{23}$} & Case series (3 & $49 / \mathrm{M}$ & Pancreatic NET & PPPD with HJstomy & 5 & Complete \\
\hline & patients) & $27 / \mathrm{M}$ & Choledochal cyst & Excision of cyst with R-Y & 5 & Complete \\
\hline & & $63 / \mathrm{F}$ & Pancreatic NET & $\begin{array}{l}\text { Whipple operation with } \\
\text { R-Y }\end{array}$ & 77 & Complete \\
\hline Liu et al. $(2019)^{70}$ & $\begin{array}{l}\text { Case report (4 } \\
\text { patients) }\end{array}$ & $\begin{array}{c}\text { Median, 69/ } \\
\mathrm{M}: \mathrm{F}=3: 1\end{array}$ & $\begin{array}{l}\text { Peri-ampullary } \\
\text { carcinoma }\end{array}$ & PPPD & N/A & Complete \\
\hline
\end{tabular}

B-II, Billroth II; CCC, cholangiocellular carcinoma; HCC, hepatocellular carcinoma; HJstomy, hepaticojejunostomy; LC, liver cirrhosis; LDLT, living-donor liver transplantation; N/A, not available; NET, neuroendocrine tumor; PPPD, pylorus-preserving pancreaticoduodenectomy; R-Y, Roux-en-Y anastomosis; VA, Vater's ampulla. 


\section{CONCLUSIONS}

MCA is a nonsurgical alternative for treating severe or completely obstructing BBSs that cannot be resolved using conventional endoscopic or percutaneous methods. MCA is safe and feasible in the management of biliobiliary and bilioenteric strictures occurring after various operations. Although an effective and reliable pre-MCA assessment method has not yet been established, modification of magnets and development of effective magnet delivery systems have increased the success rate of MCA. The understanding of the mechanisms and principles of MCA by endoscopists can expand the clinical indications of MCA and enable further applications and developments of this method.

\section{Conflicts of Interest}

The authors have no financial conflicts of interest.

\section{ORCID}

Jae Hee Cho: https://orcid.org/0000-0003-4174-0091

Dong Ki Lee: https://orcid.org/0000-0002-0048-9112

\section{REFERENCES}

1. Martins FP, De Paulo GA, Contini MLC, Ferrari AP. Metal versus plastic stents for anastomotic biliary strictures after liver transplantation: a randomized controlled trial. Gastrointest Endosc 2018;87: 131.e1-e131.e13.

2. Brunet M, Blouin Y, Mosimann F. Biliary strictures after cholecystectomy: long term results of a novative endoscopic treatment. Hepatogastroenterology 2014;61:2203-2208.

3. Marcos A, Fisher RA, Ham JM, et al. Liver regeneration and function in donor and recipient after right lobe adult to adult living donor liver transplantation. Transplantation 2000;69:1375-1379.

4. Sanchez-Urdazpal L, Gores GJ, Ward EM, et al. Diagnostic features and clinical outcome of ischemic-type biliary complications after liver transplantation. Hepatology 1993;17:605-609.

5. Schwartz DA, Petersen BT, Poterucha JJ, Gostout CJ. Endoscopic therapy of anastomotic bile duct strictures occurring after liver transplantation. Gastrointest Endosc 2000;51:169-174.

6. Yoshimoto T, Yazumi S, Hisatsune H, Egawa H, Maetani Y, Chiba T. Crane-neck deformity after right lobe living donor liver transplantation. Gastrointest Endosc 2006;64:271.

7. Kim HJ, Park DI, Park JH, et al. Multidetector computed tomography cholangiography with multiplanar reformation for the assessment of patients with biliary obstruction. J Gastroenterol Hepatol 2007;22:400-405.

8. Pasha SF, Harrison ME, Das A, et al. Endoscopic treatment of anastomotic biliary strictures after deceased donor liver transplantation: outcomes after maximal stent therapy. Gastrointest Endosc 2007;66:44-51.

9. Shah SA, Grant DR, McGilvray ID, et al. Biliary strictures in 130 consecutive right lobe living donor liver transplant recipients: results of a Western center. Am J Transplant 2007;7:161-167.

10. Venu M, Brown RD, Lepe R, et al. Laboratory diagnosis and nonoperative management of biliary complications in living donor liver transplant patients. J Clin Gastroenterol 2007;41:501-506.

11. Avaliani M, Chigogidze N, Nechipai A, Dolgushin B. Magnetic compression biliary-enteric anastomosis for palliation of obstructive jaundice: initial clinical results. J Vasc Interv Radiol 2009;20:614-623.
12. Graziadei IW, Schwaighofer H, Koch R, et al. Long-term outcome of endoscopic treatment of biliary strictures after liver transplantation. Liver Transpl 2006;12:718-725.

13. Wang SP, Yan XP, Xue F, et al. Fast magnetic reconstruction of the portal vein with allogeneic blood vessels in canines. Hepatobiliary Pancreat Dis Int 2015;14:293-299.

14. Matsuno N, Uchiyama M, Nakamura Y, et al. A nonsuture anastomosis using magnetic compression for biliary stricture after living donor liver transplantation. Hepatogastroenterology 2009;56:47-49.

15. Yamanouchi E. A new interventional method: magnetic compression anastomosis with rare-earth magnets. Cardiovasc Intervent Radiol 1998;21(Suppl 1):S155.

16. Yamanouchi E, Kumano R, Kobayashi K, et al. [Treatment for bowel or biliary obstruction by magnetic compression anastomosis development of Yamanouchi's method and its clinical evaluation]. J Nippon Med Sch 2002;69:471-475

17. Mimuro A, Tsuchida A, Yamanouchi E, et al. A novel technique of magnetic compression anastomosis for severe biliary stenosis. Gastrointest Endosc 2003;58:283-287.

18. Itoi $\mathrm{T}$, Yamanouchi E, Ikeda $\mathrm{T}$, et al. Magnetic compression anastomosis: a novel technique for canalization of severe hilar bile duct strictures. Endoscopy 2005;37:1248-1251.

19. Muraoka N, Uematsu H, Yamanouchi E, et al. Yamanouchi magnetic compression anastomosis for bilioenteric anastomotic stricture after living-donor liver transplantation. J Vasc Interv Radiol 2005;16:1263-1267.

20. Yukawa N, Rino Y, Yamanouchi E, et al. [A case of magnetic compression anastomosis between the common bile duct and the duodenum after distal gastrectomy with Roux-Y reconstruction and cholecystectomy]. Nihon Shokakibyo Gakkai Zasshi 2008;105:1523-1528.

21. Takao S, Matsuo Y, Shinchi H, et al. Magnetic compression anastomosis for benign obstruction of the common bile duct. Endoscopy 2001;33:988-990.

22. Jang SI, Kim JH, Won JY, et al. Magnetic compression anastomosis is useful in biliary anastomotic strictures after living donor liver transplantation. Gastrointest Endosc 2011;74:1040-1048.

23. Jang SI, Rhee K, Kim H, et al. Recanalization of refractory benign biliary stricture using magnetic compression anastomosis. Endoscopy 2014;46:70-74

24. Jang SI, Lee KH, Yoon HJ, Lee DK. Treatment of completely obstructed benign biliary strictures with magnetic compression anastomosis: follow-up results after recanalization. Gastrointest Endosc 2017;85:10571066.

25. Dumonceau JM, Devière J, Delhaye M, Baize M, Cremer M. Plastic and metal stents for postoperative benign bile duct strictures: the best and the worst. Gastrointest Endosc 1998;47:8-17.

26. Bonnel DH, Liguory CL, Lefebvre JF, Cornud FE. Placement of metallic stents for treatment of postoperative biliary strictures: long-term outcome in 25 patients. AJR Am J Roentgenol 1997;169:1517-1522.

27. Ernst O, Sergent G, Mizrahi D, Delemazure O, L'Herminé C. Biliary leaks: treatment by means of percutaneous transhepatic biliary drainage. Radiology 1999;211:345-348.

28. Vogel SB, Howard RJ, Caridi J, Hawkins IF Jr. Evaluation of percutaneous transhepatic balloon dilatation of benign biliary strictures in highrisk patients. Am J Surg 1985;149:73-79.

29. Mita A, Hashikura Y, Masuda Y, et al. Nonsurgical policy for treatment of bilioenteric anastomotic stricture after living donor liver transplantation. Transpl Int 2008;21:320-327.

30. Okajima H, Kotera A, Takeichi T, et al. Magnet compression anastomosis for bile duct stenosis after duct-to-duct biliary reconstruction in living donor liver transplantation. Liver Transpl 2005;11:473-475.

31. Oya H, Sato Y, Yamanouchi E, et al. Magnetic compression anastomosis for bile duct stenosis after donor left hepatectomy: a case report. Transplant Proc 2012;44:806-809.

32. Suyama K, Takamori H, Yamanouchi E, et al. Recanalization of obstruct- 
ed choledochojejunostomy using the magnet compression anastomosis technique. Am J Gastroenterol 2010;105:230-231.

33. Itoi T, Yamanouchi E, Ikeuchi N, Kasuya K, Iwamoto H, Tsuchida A. Magnetic compression duct-to-duct anastomosis for biliary obstruction in a patient with living donor liver transplantation. Gut Liver 2010;4(Suppl 1):S96-S98.

34. Jang SI, Choi J, Lee DK. Magnetic compression anastomosis for treatment of benign biliary stricture. Dig Endosc 2015;27:239-249.

35. Jang SI, Lee KH, Joo SM, Park H, Choi JH, Lee DK. Maintenance of the fistulous tract after recanalization via magnetic compression anastomosis in completely obstructed benign biliary stricture. Scand J Gastroenterol 2018;53:1393-1398.

36. Kao D, Zepeda-Gomez S, Tandon P, Bain VG. Managing the post-liver transplantation anastomotic biliary stricture: multiple plastic versus metal stents: a systematic review. Gastrointest Endosc 2013;77:679-691.

37. Thuluvath PJ, Pfau PR, Kimmey MB, Ginsberg GG. Biliary complications after liver transplantation: the role of endoscopy. Endoscopy 2005;37:857-863.

38. Zoepf T, Maldonado-Lopez EJ, Hilgard P, et al. Balloon dilatation vs. balloon dilatation plus bile duct endoprostheses for treatment of anastomotic biliary strictures after liver transplantation. Liver Transpl 2006;12:88-94.

39. Sharma S, Gurakar A, Jabbour N. Biliary strictures following liver transplantation: past, present and preventive strategies. Liver Transpl 2008;14:759-769.

40. Tal AO, Finkelmeier F, Filmann N, et al. Multiple plastic stents versus covered metal stent for treatment of anastomotic biliary strictures after liver transplantation: a prospective, randomized, multicenter trial. Gastrointest Endosc 2017;86:1038-1045.

41. Akita H, Hikita H, Yamanouchi E, et al. Use of a metallic-wall stent in the magnet compression anastomosis technique for bile duct obstruction after liver transplantation. Liver Transpl 2008;14:118-120.

42. Ersoz G, Tekin F, Bozkaya H, et al. Magnetic compression anastomosis for patients with a disconnected bile duct after living-donor related liver transplantation: a pilot study. Endoscopy 2016;48:652-656.

43. Parlak E, Koksal AS, Kucukay F, Eminler AT, Toka B, Uslan MI. A novel technique for the endoscopic treatment of complete biliary anastomosis obstructions after liver transplantation: through-the-scope magnetic compression anastomosis. Gastrointest Endosc 2017;85:841-847.

44. Jiang XM, Yamamoto K, Tsuchiya T, et al. Magnetic compression anastomosis for biliary obstruction after partial hepatectomy. Endoscopy 2018;50:E144-E145.

45. Li Y, Sun H, Yan X, et al. Magnetic compression anastomosis for the treatment of benign biliary strictures: a clinical study from China. Surg Endosc 2020;34:2541-2550.

46. Weber A, Zellner S, Wagenpfeil S, et al. Long-term follow-up after endoscopic stent therapy for benign biliary strictures. J Clin Gastroenterol 2014;48:88-93.

47. Dumonceau JM, Tringali A, Blero D, et al. Biliary stenting: indications, choice of stents and results: European Society of Gastrointestinal Endoscopy (ESGE) clinical guideline. Endoscopy 2012;44:277-298.

48. Schumacher B, Othman T, Jansen M, Preiss C, Neuhaus H. Long-term follow-up of percutaneous transhepatic therapy (PTT) in patients with definite benign anastomotic strictures after hepaticojejunostomy. Endoscopy 2001;33:409-415.

49. Weber A, Rosca B, Neu B, et al. Long-term follow-up of percutaneous transhepatic biliary drainage (PTBD) in patients with benign bilioenterostomy stricture. Endoscopy 2009;41:323-328.

50. Bonnel DH, Fingerhut AL. Percutaneous transhepatic balloon dilatation of benign bilioenteric strictures: long-term results in 110 patients. Am J Surg 2012;203:675-683.

51. Costamagna G, Boškoski I. Current treatment of benign biliary strictures. Ann Gastroenterol 2013;26:37-40.

52. Kato H, Kawamoto H, Tsutsumi K, et al. Long-term outcomes of endo- scopic management for biliary strictures after living donor liver transplantation with duct-to-duct reconstruction. Transpl Int 2009;22:914921.

53. Chang JH, Lee IS, Choi JY, et al. Biliary stricture after adult right-lobe living-donor liver transplantation with duct-to-duct anastomosis: longterm outcome and its related factors after endoscopic treatment. Gut Liver 2010;4:226-233.

54. Elwir S, Thompson J, Amateau SK, et al. Endoscopic management of biliary leaks and strictures after living donor liver transplantation: optimizing techniques for successful management. Dig Dis Sci 2017;62:244252.

55. Melcher ML, Pomposelli JJ, Verbesey JE, et al. Comparison of biliary complications in adult living-donor liver transplants performed at two busy transplant centers. Clin Transplant 2010;24:E137-E144.

56. Rao J, Sun Y, Zhou H, et al. Remain recipient partial liver during liver transplant after Hassab. J Surg Res 2014;189:321-325.

57. Gondolesi GE, Varotti G, Florman SS, et al. Biliary complications in 96 consecutive right lobe living donor transplant recipients. Transplantation 2004;77:1842-1848.

58. Kasahara M, Egawa $\mathrm{H}$, Takada $\mathrm{Y}$, et al. Biliary reconstruction in right lobe living-donor liver transplantation: comparison of different techniques in 321 recipients. Ann Surg 2006;243:559-566.

59. Tsujino T, Isayama H, Sugawara $Y$, et al. Endoscopic management of biliary complications after adult living donor liver transplantation. Am J Gastroenterol 2006;101:2230-2236.

60. Yazumi S, Yoshimoto T, Hisatsune H, et al. Endoscopic treatment of biliary complications after right-lobe living-donor liver transplantation with duct-to-duct biliary anastomosis. J Hepatobiliary Pancreat Surg 2006;13:502-510.

61. Tashiro H, Itamoto T, Sasaki T, et al. Biliary complications after duct-toduct biliary reconstruction in living-donor liver transplantation: causes and treatment. World J Surg 2007;31:2222-2229.

62. Londoño MC, Balderramo D, Cárdenas A. Management of biliary complications after orthotopic liver transplantation: the role of endoscopy. World J Gastroenterol 2008;14:493-497.

63. Ohkubo M, Nagino M, Kamiya J, et al. Surgical anatomy of the bile ducts at the hepatic hilum as applied to living donor liver transplantation. Ann Surg 2004;239:82-86.

64. Archer SB, Brown DW, Smith CD, Branum GD, Hunter JG. Bile duct injury during laparoscopic cholecystectomy: results of a national survey. Ann Surg 2001;234:549-558; discussion 558-559.

65. Bismuth H, Majno PE. Biliary strictures: classification based on the principles of surgical treatment. World J Surg 2001;25:1241-1244.

66. Strasberg SM, Hertl M, Soper NJ. An analysis of the problem of biliary injury during laparoscopic cholecystectomy. J Am Coll Surg 1995;180:101-125.

67. Way LW, Stewart L, Gantert W, et al. Causes and prevention of laparoscopic bile duct injuries: analysis of 252 cases from a human factors and cognitive psychology perspective. Ann Surg 2003;237:460-469.

68. Fiocca F, Salvatori FM, Fanelli F, et al. Complete transection of the main bile duct: minimally invasive treatment with an endoscopic-radiologic rendezvous. Gastrointest Endosc 2011;74:1393-1398.

69. Devière J. Benign biliary strictures and leaks. Gastrointest Endosc Clin N Am 2015;25:713-723.

70. Liu XM, Li Y, Xiang JX, et al. Magnetic compression anastomosis for biliojejunostomy and pancreaticojejunostomy in Whipple's procedure: an initial clinical study. J Gastroenterol Hepatol 2019;34:589-594.

71. Itoi T, Kasuya K, Sofuni A, et al. Magnetic compression anastomosis for biliary obstruction: review and experience at Tokyo Medical University Hospital. J Hepatobiliary Pancreat Sci 2011;18:357-365.

72. Lim HC, Lee DK, Choi HK, et al. [Magnet compression anastomosis for bilioenteric anastomotic stricture after removal of a choledochal cyst: a case report]. Korean J Gastrointest Endosc 2010;41:180-184. 